\title{
Políticas públicas para a agricultura familiar no município de Entre Rios do Oeste: uma análise a partir da teoria ator orientado
}

\author{
Fabíola Graciele BESEN ${ }^{1 *}$, Adilson Francelino ALVES ${ }^{2}$, Juarez BORTOLANZA \\ Tércio Vieira de ARAÚJO ${ }^{1}$, Valdir SERAFIM JUNIOR ${ }^{1}$ \\ ${ }^{1}$ Universidade Estadual do Oeste do Paraná, Foz do Iguaçu, PR, Brasil. \\ ${ }^{2}$ Universidade Estadual do Oeste do Paraná, Francisco Beltrão, PR, Brasil. \\ ${ }^{3}$ Universidade Estadual do Oeste do Paraná, Marechal Candido Rondon, PR, Brasil. \\ *E-mail: fabiolagracielebesen@gmail.com
}

Recebido em dezembro/2017; Aceito em junho/2018.

\begin{abstract}
RESUMO: O objetivo geral deste artigo é analisar as políticas públicas disponibilizadas para o agricultor familiar, visando a permanência do homem no campo. Para tal, fez-se o estudo no município de Entre Rios do Oeste durante o período de 2013/2016, uma apreciação das políticas públicas ofertadas pelo município e como os agricultores familiares são beneficiários dessas políticas. O estudo desenvolveu-se acerca do seguinte problema de pesquisa: As políticas públicas voltadas a agricultura familiar no município de Entre Rios do Oeste contribuem para o desenvolvimento dos agricultores familiares associados a APOER (atores beneficiários) mantendo-os na área rural com diversidade de renda pelas ações promovidas? O estudo foi realizado com agricultores familiares agroecológicos associados à APOER - Associação dos Produtores Orgânicos de Entre Rios do Oeste. Como embasamento teórico fez-se uso da Teoria Ator Orientado de Norman Long. A pesquisa se classifica como bibliográfica, descritiva e exploratória quanto aos objetivos, com abordagem quantitativa e qualitativa e as técnicas utilizadas são análise documental e entrevista com formulário semiestruturado. Através da pesquisa realizada, pode-se concluir que os produtores foram contemplados pelas diferentes políticas públicas atendendo alguns dos objetivos, interesses e expectativas dos mesmos conforme os relatos e que as políticas públicas não devem ser projetos com limites no espaço e tempo, mas devem ser construídos por todos os agentes considerando as estratégias, práticas e motivações dos atores locais para galgar os resultados esperados.
\end{abstract}

Palavras-chave: agricultor familiar, governo, atores.

\section{Public policies for family agriculture in the municipality of Entre Rios Do Oeste: an analysis from the oriented actor theory}

\begin{abstract}
The general objective of this article is to analyze the public policies available to the family farmer, aiming at the permanence of the man in the field. To do this, the study was conducted in the municipality of entre rios do oeste during the period 2013/2016, an appreciation of the public policies offered by the municipality and how family farmers are beneficiaries of these policies. The study focused on the following research problem: public policies aimed at family farming in the municipality of entre rios do oeste contribute to the development of family farmers associated with apoer (beneficiary actors), keeping them in rural areas with income diversity for the promoted actions? The study was carried out with agroecological family farmers associated to apoer association of organic producers of entre rios do oeste. As a theoretical background, norman long's oriented actor theory was used. The research is classified as bibliographic, descriptive and exploratory regarding the objectives, with quantitative and qualitative approach and the techniques used are documental analysis and semi structured interview. Through the research carried out, it can be concluded that the producers were contemplated by the different public policies, meeting some of their objectives, interests and expectations according to the reports and that public policies should not be projects with limits in space and time, but should be constructed by all the agents considering the strategies, practices and motivations of the local actors to achieve the expected results.

Keywords: family farmer, government, actors.
\end{abstract}

\section{INTRODUÇÃO}

Do ponto de vista econômico, conforme o último Censo Agropecuário (IBGE, 2006) 85\% do total das propriedades rurais do país pertencem a grupos familiares enquadrados como agricultores familiares. Estes ocupam $24,3 \%$ da área total, representam $74,4 \%$ das pessoas ocupadas e respondem por $38 \%$ do Valor Bruto da Produção. Mas do ponto de vista histórico, a Agricultura Familiar até a década de 1990 sempre esteve à margem das políticas públicas, embora seja uma forma de vida de milhares de homens e mulheres que sobreviveu ao longo do tempo.

Segundo Guilhoto et al. (2007, p.13),"o setor agropecuário familiar é sempre lembrado por sua importância na absorção de empregos e na produção de alimentos, voltada especialmente para o autoconsumo". Porém devido a sua baixa capacidade produtiva de trabalho e menores condições de aquisição tecnológica, ela é focada mais no caráter social do que o econômico. 
Assim, a agricultura familiar encontra dificuldades para competir com a agricultura patronal, e por essa razão, torna-se necessária a criação de políticas públicas adequadas a esse público.

Por essa razão, o conjunto de políticas públicas e programas governamentais com o intuito de proporcionar a permanência do homem no campo com boa qualidade de vida, e promover diversidade de renda e formas de produção direcionadas ao bem-estar da sociedade, exigiram que novos procedimentos administrativos fossem efetivados (ARAÚJO, 2009). Em 1996, criou-se o PRONAF (Programa Nacional de Fortalecimento da Agricultura Familiar). Esse programa foi emblemático, foi o pioneiro a destinar recursos públicos específicos do sistema de crédito para a categoria de agricultores familiares.

Foi a partir da década de 1990, com o Censo e a criação do PRONAF, que a Agricultura Familiar passou a ser conceituada e estudada, e embora, ela sempre tenha existido, contudo foi apenas a partir desse período, que se criou uma identidade para a mesma, o que possibilitou a construção de políticas públicas específicas para atender esse grupo social em suas especificidades (GRISA; SCHNEIDER, 2015).

Embora nas duas últimas décadas tenha havido uma evolução das políticas públicas para a agricultura familiar, e que as mesmas sofreram várias reformulações, no sentido de atender melhor aos interesses do Estado e dos agricultores, deve-se verificar se essas políticas atendem as necessidades dos agricultores.

A partir desses apontamentos surge a necessidade de um referencial teórico-metodológico que permita analisar essas políticas e busque fazer uma análise das intenções como parte do processo e não como algo pronto. Assim, uma teoria para analisar e entender conflitos e negociações no processo de implementação de estratégias e políticas de desenvolvimento rural é a Teoria Ator Orientado ou Perspectiva Orientada ao Ator (POA), proposta pelo antropólogo Norman Long (LONG, 2001).

A Teoria Ator Orientado desenvolvida por Norman Long (2001) é importante, pois ela trata do processo de desenvolvimento e de mudança social. O objetivo de Long ao propor essa teoria foi entender os processos de mudança pelos quais as formas sociais surgem, são transformadas e retransformadas na vida cotidiana das pessoas. O enfoque orientado ao ator encontra espaço para análise da multiplicidade de racionalidades, desejos, capacidades e práticas. A proposta é dialogar com essa teoria buscando uma abordagem orientada aos atores. Uma perspectiva orientada aos atores parte do pressuposto de que diferentes agricultores (ou categorias de agricultores) definem e operacionalizam seus objetivos e práticas de gerenciamento agrícola com base em diferentes critérios, interesses, experiências e perspectivas (LONG; PLOEG, 2011).

A apropriação da teoria de Norman Long, relacionada as políticas públicas para agricultura familiar, com a aplicação de seus conceitos será no município de Entre Rios do Oeste, selecionado para este trabalho. Assim, o presente trabalho tem por objetivo principal responder a seguinte pergunta de pesquisa: As políticas públicas voltadas a agricultura familiar no município de Entre Rios do Oeste contribuem para o desenvolvimento dos agricultores familiares associados a APOER (atores beneficiários) mantendo-os na área rural com diversidade de renda pelas ações promovidas?
Considerando a problemática de pesquisa, tornou-se possível definir como objetivo geral analisar as políticas públicas disponibilizadas para o agricultor familiar associado a APOER (ator beneficiado) no município de Entre Rios do Oeste e compreender se as mesmas estão contribuindo no sentido da sua permanência e sustentabilidade no campo à luz dos conceitos da Teoria Ator Orientado. O presente estudo se justifica pela importância social e econômica que possui a agricultura familiar no Brasil e esse (re) nascimento da temática agricultura familiar no âmbito dos estudos rurais brasileiros que remete a questionamentos sobre o futuro dessa forma social de produção e trabalho. Conforme Schneider (2005), a agricultura familiar produz e fornece alimentos básicos de preço acessível e de boa qualidade para a população. Dessa forma, também se justifica pelo papel que a agricultura familiar vem assumindo em relação à segurança alimentar e nutricional da população.

Para classificação das unidades de agricultura familiar, foi considerado o conceito de agricultura familiar conforme a Lei $\mathrm{n}^{\mathrm{o}}$ 11.326/2006, também conhecida como "Lei da Agricultura Familiar", criada em 2006 e que considera agricultor familiar:

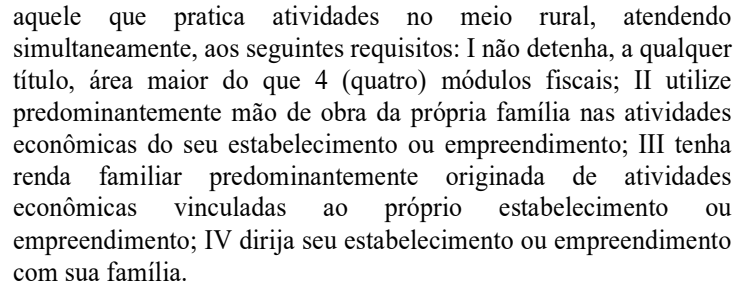
simultaneamente, aos seguintes requisitos: I não detenha, a qualquer título, área maior do que 4 (quatro) módulos fiscais; II utilize predominantemente mão de obra da própria família nas atividades econômicas do seu estabelecimento ou empreendimento; III tenha renda familiar predominantemente originada de atividades econômicas vinculadas ao próprio estabelecimento ou empreendimento; IV dirija seu estabelecimento ou empreendimento com sua família.

Outro fator que chamou a atenção para o desenvolvimento da pesquisa refere-se aos trabalhos já desenvolvidos na área a partir da Teoria Ator Orientado. González et al. (2013), Schneider; Gazolla (2011) afirmam que os estudos sobre a Teoria Ator Orientado no espaço rural, vêm se ampliando entre pesquisadores brasileiros, principalmente na Universidade Federal do Rio Grande do Sul.

Estes autores organizaram o livro "Os atores do desenvolvimento rural", onde os mesmos mostram diferentes experiências que lhes permite concluir que os agricultores são atores sociais que têm capacidade de responder aos desafios e questões colocadas em sua época (SCHNEIDER; GAZOLLA, 2011). "Conterato et al., 2003, Gazolla e Peregrini (2001) e Marques (2009) também utilizaram a Perspectiva Orientada ao Ator com a noção de produção de novidades." (GONZÁLEZ et al., p.115). Deponti (2010) fez um estudo acerca da análise sobre o programa de extensão rural do Rio Grande do Sul. Utilizou a Teoria Ator Orientado e em sua conclusão afirmou que ela contribui no estudo de conflitos a partir do conceito de arena pois "envolve uma proposta de desenvolvimento, abrindo espaço para a compreensão da complexidade da intervenção, valorizando o espaço para manobra e superando as análises que consideram o jogo social antecipadamente definido." (Deponti, 2010, p.223-224) (GONZÁLEZ et al., 2013, p.115).

\section{MATERIAL E MÉTODOS}

A abordagem da pesquisa se deu pelo enfoque qualiquanti. Segundo Oliveira (2007, p. 39), "[...] o método quantitativo "caracteriza-se pelo emprego da quantificação tanto nas modalidades de coleta de informações quanto no tratamento delas". Esta pesquisa se caracteriza como 
quantitativa decorrente da análise dos dados do orçamento público, políticas públicas e dados dos agricultores familiares inseridos em software de gerenciamento estatístico. Conforme Beuren (2008, pág. 92): “A abordagem qualitativa visa destacar características não observadas por meio de estudo quantitativo, haja vista a superficialidade desta última". Aplicou-se a abordagem qualitativa ao buscar o entendimento dos fenômenos por meio de interpretações de opiniões e percepções através das análises das entrevistas com os beneficiários.

A técnica utilizada é a análise documental que consiste em uma série de operações que visam estudar e analisar um ou vários documentos para descobrir as circunstâncias sociais e econômicas com as quais podem estar relacionados (RICHARDSON, 2009, p. 230). No primeiro momento esta pesquisa utilizou a técnica de pesquisa documental, baseada em documentos (dados secundários) como fonte de coleta de dados. Os dados secundários são os relatórios - Quadros de detalhamento de despesas, (Portal de Transparência do município), que foram coletados e analisados. Os dados coletados, políticas e valores do orçamento destinados as políticas foram tabuladas em uma planilha eletrônica. Uma vez identificadas as políticas públicas o passo seguinte foi entrevistar os atores-chave dessas políticas: os agricultores beneficiários

A coleta de dados primários foi obtida por meio de entrevista (formulário semi-estruturado) e em seguida por uma conversa informal, feito pelo próprio pesquisador, em contato direto com os entrevistados para identificar as políticas públicas acessadas pelos mesmos. Conforme Cervo e Bervian (2002, p.105) a entrevista é "uma conversa orientada para um objetivo definido: recolher, através do interrogatório do informante, dados para a pesquisa. As informações obtidas nas entrevistas foram realizadas no diário de campo do próprio entrevistador. Essa técnica, se comparada à gravação, capta menos informações, mas apresenta a vantagem de não inibir o entrevistado. Uma vez que não é necessário fazer a transcrição das entrevistas, facilita e agiliza a análise dos dados.

Quanto à população ou universo de pesquisa, segundo Beuren (2008, p.118) " [...] é a totalidade de elementos distintos que possuem certa paridade nas características definidas para determinado estudo [...] ". O universo de pesquisa são os 26 produtores associados a APOER (Associação dos Produtores Orgânicos de Entre Rios do Oeste).

3. DISCUSSÃO SOBRE O PROCESSO DE DESENVOLVIMENTO RURAL, POLÍTICAS PÚBLICAS PARA A AGRICULTURA FAMILIAR E A ABORDAGEM DA TEORIA ATOR ORIENTADO: UMA REVISÃO CONCEITUAL

\subsection{Desenvolvimento Rural}

Como apresenta Ellis e Biggs (2001) o desenvolvimento rural teve ao longo dos últimos cinquenta anos períodos bem distintos: a década de 1950 representou o início do processo de modernização da agricultura e o camponês desempenhava apenas um papel passivo no processo de desenvolvimento econômico, como fornecedor de recursos.

Nesse contexto, cabe destacar uma visão geral dos principais temas sobre desenvolvimento rural, dominantes e secundários que ocorreram ao longo dos últimos 50 anos, a partir da discussão de Frank Ellis e Stephen Biggs (2001).
Ellis; Biggs (2001) afirmam que no início da década de 50, o desenvolvimento rural pautava-se na ideia que a maioria dos agricultores, chamados de 'subsistência' ou 'tradicionais' não acompanhariam o desenvolvimento econômico, nem seriam capazes de aumentar a produtividade. O papel deles era secundário, quer dizer, seriam fornecedores de recursos para o setor moderno da economia. Este setor moderno constituído pelas grandes propriedades rurais e com uma agricultura em larga escala, poderiam fazer uso mais eficiente dos recursos e tecnologias modernas, e assim tomaria o lugar das pequenas propriedades rurais.

Percebe-se que a partir dessa visão "de agricultores ideais", desconsiderava-se totalmente os atores envolvidos no meio rural e seus interesses, pois o governo buscava classificar os agricultores a partir de sua visão para a construção das políticas públicas.

Em meados da década de 1960, ocorreu a primeira mudança de paradigma, pois a pequena propriedade passou a ser considerada o motor do crescimento e desenvolvimento.

Essa mudança de abordagem que passou a dar mais importância a agricultura de pequena escala, acabou por integrá-la à dinâmica de desenvolvimento com a abertura de linhas de crédito e políticas de assistência técnica destinadas à difusão das técnicas e práticas da revolução verde. Embora comece a ocorrer a mudança, ela não se faz sentir imediatamente nas políticas públicas, pois ainda prevalecia a ideia de que a agricultura em grande escala utilizando a tecnologia era mais eficiente do que o setor 'camponês', durante a década de 70 (ELLIS; BIGGS, 2001).

A segunda mudança de paradigma ocorreu entre os anos de 1980 e 1990, em que a abordagem que era de cima para baixo se torna uma abordagem de baixo para cima, quer dizer, o desenvolvimento rural é visto como um processo participativo que capacita moradores rurais para assumir o controle de suas próprias prioridades para a mudança.

Outro fator a ser destacado neste período, mais precisamente em 1987, quando a Comissão Mundial do Meio Ambiente publicou o relatório denominado 'Nosso futuro comum' que trata da formulação dos princípios do desenvolvimento sustentável.

Os principais objetivos de políticas derivados deste conceito de desenvolvimento e que foram recomendados pela Comissão eram: retomar o crescimento como condição necessária para erradicar a pobreza; mudar a qualidade do crescimento para torná-lo mais justo, equitativo e menos intensivo em matérias primas e energia; atender às necessidades humanas essenciais de emprego, alimentação, água e saneamento; manter um nível populacional sustentável; conservar e melhorar a base de recursos; reorientar a tecnologia e administrar os riscos; e incluir o meio ambiente e a economia no processo decisório (COMISSÃO MUNDIAL SOBRE MEIO AMBIENTE E DESENVOLVIMENTO, 1991).

\subsection{O desenvolvimento rural e a Teoria Ator Orientado}

A mudança de paradigma que ocorreu no desenvolvimento rural alterou o olhar sobre os pequenos agricultores. Segundo Schmitt (2011, p.89) "os debates nas últimas décadas foram revitalizados por novas abordagens teóricas e metodológicas, traduzidas em uma ampla gama de estudos de caso, análises comparativas, reflexões de natureza metodológica e esforços de teorização". 
Dessa forma, a Teoria Ator Orientado é importante, porque trata o processo de desenvolvimento e de mudança social pela ótica tanto dos implantadores de políticas públicas quanto pelos beneficiários destas. O objetivo de Long ao propor essa teoria foi entender os processos de mudança pelos quais as formas sociais surgem, são transformadas e retransformadas na vida cotidiana das pessoas. $\mathrm{O}$ enfoque orientado ao ator encontra espaço para análise da multiplicidade de racionalidades, desejos, capacidades e práticas (LONG, 2001).

Dentre as contribuições da teoria de Norman Long está o conceito de 'campos de batalha do conhecimento' para explicar o espaço em que os atores são confrontados com as experiências, interesses e valores uns dos outros. Nessa arena, também se encontram os dilemas e desafios institucionalmente construídos, as políticas públicas, ONGs, pesquisas acadêmicas e de órgãos de fomento, dentre outros que fazem parte do debate. Estes campos não se restringem somente ao local e podem fazer parte de projetos maiores que tentam abarcar um grande número de atores sociais. Um exemplo disso, nas políticas públicas da Agricultura Familiar, é o Programa Nacional de Alimentação Escolar (PNAE) e o Programa de Aquisição de Alimentos (PAA) (ALVES, 2008).

Para Long (2002), os programas devem ser desconstruídos, para mostrar a sua realidade: programas socialmente construídos, negociados e processados, e não apenas planos que devem vir de cima para baixo. Quer dizer, os projetos para a agricultura não devem ser impostos por atores externos mais poderosos.

Ainda de acordo com Long; Van Der Ploeg (2011), os agricultores passam a ser vistos como atores sociais, e não mais como recipientes vazios ou passivos de intervenção. "Eles se tornam participantes ativos que processam informações e utilizam estratégias nas suas relações com vários atores locais, assim como com instituições e pessoas externas" (LONG; PLOEG, 2011, p.24).

Segundo Long (2007), olhar os processos de desenvolvimento a partir da Teoria Ator Orientado significa pensar e explicar as respostas diferentes dadas a circunstâncias estruturais similares, mesmo quando as condições em que essas circunstâncias ocorrem pareçam homogêneas. As respostas diferentes seriam em parte, criação coletiva dos próprios atores, os quais não podem ser considerados como tábuas rasas, passivos de intervenções, mas sim como atores ativos, os quais recebem informações, as interpretam, e formulam estratégias em suas relações com outros atores, presentes ou ausentes, mas exercendo influências nestas relações. A perspectiva orientada para o ator que Long (2007) apud ALVES (2008) propõe fundamenta-se em alguns conceitos chave tais como:

- Heterogeneidade: A vida social é heterogênea, mesmo quando as condições parecem homogêneas, e é preciso estudar como essas diferenças se produzem, reproduzem, consolidam-se e se transformam, e também identificar os processos sociais envolvidos;

- Agência: Esta perspectiva requer uma teoria de agência em que seja atribuída a cada ator capacidade de processar, ordenar e sistematizar suas experiências sociais, aprendendo com as experiências dos outros e atuando sobre elas;

- Ação Social: A ação social nunca é individual. Ela ocupa lugar nas redes de relações, em que componentes humanos e não humanos são envolvidos. A ação social se forma pela rotina e pelas práticas organizativas exploratórias limitadas por convenções sociais, valores e relações de poder. Segundo Long (2002), essas limitações não podem se reduzir a categorias sociológicas baseadas em classe, gênero, status, etnia, dentre outros. A ação social e a interpretação são produtos gerados em contextos específicos e para não cair em prejulgamentos generalizantes, deve-se fazer análises das especificidades e particularidades das arenas e campos de ação social.

- Culturas e significados: Os significados, valores e interpretações não se constroem apenas culturalmente, mas são aplicados e reinterpretados de acordo com possibilidades ou circunstâncias existentes, o que pode gerar novos padrões culturais;

- Interface social: Para examinar essas relações, trabalhase com o conceito de interface social, que explora as formas pelas quais as discrepâncias de interesse social, interpretação cultural, conhecimento e poder são mediadas, perpetuadas ou transformadas em pontos críticos de articulação ou de confronto.

$\mathrm{O}$ ator social, por sua vez, existe sob várias formas (indivíduos, redes, organizações, pessoas individuais, grupos informais, redes) e podem ser os chamados macro-atores (governos nacionais, igrejas, ONGs). O ator social possui capacidade de saber e de atuar, tentar resolver problemas, aprende a intervir no seu entorno, e age por conta própria, mesmo limitado em termos de informação, incerteza e restrições físicas, normativas, políticas e econômicas. (KRUEL, 2010) Assim, "a agência [...] está encarnada nas relações sociais, e só pode ser efetiva através delas" (LONG, 2007, p.50).

Nem todos os atores sociais atuam em uníssono, pois eles possuem mundos sociais diferentes (relações próprias, experiências que incluem ações, interações e significados, e se identificam com espaços sociais, geográficos e com histórias de vida) e tem seus próprios modos de vida (sustento, renda, formas de lidar com as adversidades, estilos de vida, culturas diferentes) para os quais adotam processos organizativos (os quais englobam práticas que implicam em cooperação, mediação e competição entre indivíduos e grupos, dentro de domínios sociais e entre eles) (KRUEL, 2010).

\subsection{A agricultura familiar e agroecologia}

No Brasil, apenas na década de 90 , com a criação do Programa Nacional de Fortalecimento da Agricultura (PRONAF) em 1995, que a agricultura familiar passou a ser vista como categoria no meio rural. (GRISA; SCHNEIDER, 2015).

O conceito do Dossiê Estatístico elaborado pelo Instituto Nacional de Colonização e Reforma Agrária - INCRA e o Fundo das Nações Unidas para a Agricultura e Alimentação FAO (1996, p.4), define a agricultura familiar a partir de três características centrais: a) a gestão da unidade produtiva são feitos por indivíduos que mantém relações de parentesco; b) a maior parte mão de obra provém da família; c) a propriedade dos meios de produção ( embora nem sempre se inclua a terra) pertence a família e sua transmissão é feita em seu interior.

Abramovay (1997) define agricultura familiar, destacando alguns aspectos relevantes: a gestão, a propriedade e o trabalho (em sua maior parte) são de indivíduos que possuem laços de 
parentesco. Nem sempre essa definição é suficiente para estabelecimento de crédito, mas [...] O importante é que estes três atributos básicos (gestão, propriedade e trabalho familiares) estão presentes em todas elas[...] (ABRAMOVAY, 1997, p. 03).

Dessa forma, observa-se que suas características principais são: a produção é orientada para o mercado, mas também para a subsistência da família, a mão de obra é predominantemente familiar, assim como a terra e os meios de produção são pertencentes a família. Diferente da agricultura empresarial que foi alvo das políticas públicas até a década de 90 , e que tem sua produção totalmente orientada para o mercado, a produção é altamente mecanizada e a mão de obra é assalariada (GRISA; SCHNEIDER, 2015).

Segundo Barrera (2011), a agroecologia desempenha um papel importante, especialmente para a agricultura familiar, pelos benefícios econômicos e os relativos à segurança alimentar e a qualidade de vida.

Assim, a agroecologia, pelas características da agricultura familiar tem o potencial de contribuir para diminuir [...] os problemas atuais da agricultura: modernização intensiva, degradação dos recursos naturais, uso crescente de agrotóxicos, diminuição da biodiversidade, impacto negativo sobre a saúde dos agricultores, contaminação de alimentos e meio ambiente [...] (SARANDON, 2009). "Embora pressionada pelos processos modernizantes, as sociedades tradicionais ainda são capazes de criar formas de resistências e sobrevivências, navegando contra a maré, num jogo entre continuidade, mudanças culturais e rupturas"(CARMO, 2008, p. 30).

Há várias definições para agroecologia. Caporal; Costabeber (2002) definem a agroecologia como um campo de conhecimento que proporciona as bases científicas para promover a transição da agricultura convencional para um estilo de agricultura agroecológica.

Para Altieri (1998, p.18) o objetivo é "trabalhar com e alimentar sistemas agrícolas complexos em que as interações ecológicas e sinergismos entre os componentes biológicos criem, eles próprios, a fertilidade do solo, a produtividade e a proteção das plantas".

Nesse sentido, pode-se entender porque os agricultores familiares são importantes para essa transição à uma agricultura sustentável, pois eles trabalham com diversidade de produção em sua propriedade. Para Caporal (2011), um dos primeiros passos é abandonar a prática da monocultura e promover a diversificação das culturas cultivadas nos sistemas de cultivo. Quanto maior a diversidade do agro ecossistema, maior será a sustentabilidade ambiental e econômica da propriedade.

\subsection{Política agrícola brasileira}

Segundo Secchi (2011), a essência das políticas públicas é o problema público. O que define se a política é pública ou não, é o objetivo de responder a um problema público, e não a classificação do ator (estatal ou não estatal). O conceito de política pública, então, está vinculado a tentativa de resolver um problema público. Para um problema ser considerado "público", os atores políticos o entendem como um problema (situação inadequada) e público (relevante para a coletividade).

No caso das políticas públicas da agricultura, no campo do desenvolvimento rural, isso significa analisar, segundo Long; Ploeg (2011, p.27) " como as concepções diferenciadas de poder, influência, conhecimento e eficácia podem modelar as respostas e estratégias dos diferentes atores (por exemplo, camponeses, proprietários de terras, representantes do governo local)".

Em resumo, a política pública existe quando há uma situação inadequada (um problema) e busca-se uma solução para esse problema, e ela se caracteriza como pública, quando os atores envolvidos (estatais e não estatais) a entendem como um problema que afeta a coletividade. As políticas públicas do meio rural sofreram alterações e aprimoramentos no decorrer das décadas com interferência da política agrícola brasileira que faz parte do cenário considerado e, estas serão contempladas no próximo item.

No caso da agricultura familiar, o seu reconhecimento perante o Estado começa a ocorrer em meados dos anos 1990, especialmente com os dados da FAO/INCRA (1996), elaborados a partir do Censo Agropecuário de 1995/96. Esses dados revelaram que, no Brasil, 85,2\% dos estabelecimentos eram familiares, ocupando $30,5 \%$ da área, responsáveis por $37,9 \%$ do VBP e que recebiam somente $25,3 \%$ dos financiamentos (GRISA; SCNHEIDER, 2015).

Diante dessa realidade, em 1996, criou-se o PRONAF (Programa Nacional de Fortalecimento da Agricultura Familiar). Esse programa foi emblemático, pois pela primeira vez, na história do Brasil destinou-se recursos públicos específicos do sistema de crédito para a categoria de agricultores familiares. Foi a partir da década de 1990, com o Censo e a criação do PRONAF, que a Agricultura Familiar passou a ser conceituada e estudada, e embora, ela sempre tenha existido, apenas a partir desse período, que se criou uma identidade para a mesma, a fim de criar políticas públicas para atendê-las (GRISA; SCNHEIDER, 2015).

Conforme Schneider, Cazella; Mattei (2004, p.23), "O PRONAF nasceu com a finalidade de prover crédito agrícola e apoio institucional aos pequenos produtores rurais que vinham sendo alijados das políticas públicas até então existentes e encontravam sérias dificuldades de se manter no campo." Foi a partir do PRONAF e da criação da Lei da Agricultura Familiar (Lei 11.326/2006), que a agricultura familiar passou a ter legitimidade e embora esse tipo de agricultura já exista há milhares de anos, dentro do Governo ela não tinha uma identidade definida. As políticas públicas até aquele momento, homogeneizaram o campo, sem levar em consideração os grupos sociais distintos que lá existiam.

A partir de 1997-1998, as políticas para agricultura familiar passaram a focar em ações sociais e assistenciais. $\mathrm{O}$ governo de Fernando Henrique Cardoso criou o Programa Comunidade Solidária, que buscou através de suas ações contemplar a questão alimentar, miséria e pobreza. No governo Lula, esse programa se consolidou com o Programa Fome Zero. Na agricultura familiar, em específico, as organizações da agricultura familiar começaram a reivindicar a necessidade de o PRONAF atender a diversidade econômica da agricultura familiar (GRISA, SCHNEIDER, 2015).

Para Grisa e Schneider (2015), as políticas com enfoque em ações de cunho social e assistencial foram fundamentais para a redução da pobreza e desigualdade rural no campo. Nas duas últimas décadas, o meio rural avançou em seus indicadores de desenvolvimento (aumento da renda, por exemplo), que talvez, não tivessem sido melhorados, se as ações fossem apenas agrícolas e agrárias.

A partir de 2003, a discussão passou a girar em torno da fome, segurança alimentar e sustentabilidade. A agricultura 
familiar passou a ter um papel de promover o acesso aos alimentos e um sistema agroalimentar mais equitativo. Essa ideia de que a agricultura familiar, através da criação de canais de comercialização e geração de renda, poderia tornar-se fornecedora de alimentos para escolas, creches, hospitais, presídios, culminou na criação do PAA - Programa de Aquisição de Alimentos (GRISA; SCHNEIDER, 2015).

O PAA, iniciado em 2003, tem o objetivo de articular a compra de alimentos da agricultura familiar para redistribuir para a população em vulnerabilidade social. Após a consolidação desse programa, e com a Lei 11.947/2009 do PNAE (Programa Nacional de Alimentação Escolar), que prevê que no mínimo $30 \%$ dos recursos federais para a alimentação escolar sejam destinados a aquisição desses alimentos é que a agricultura familiar passou a ser ator nas políticas públicas (GRISA; SCHNEIDER, 2015).

Grisa; Schneider (2015, p. 139) afirmam que "estas ações (PAA e PNAE) têm contribuído para a valorização da produção local/ regional, ecológica/orgânica e têm ressignificado os produtos da agricultura familiar, promovendo novos atributos de qualidade aos mesmos, associados, por exemplo, à justiça social, equidade, artesanalidade, cultura tradição etc."

$\mathrm{O}$ entendimento das ocorrências no meio rural através da Teoria Ator Orientado busca compreender os fenômenos evolutivos ocorridos na agricultura e nas pequenas propriedades rurais, diante das políticas governamentais, ou a inexistência das mesmas, o que proporcionou mecanismos de interação entre os atores de suas próprias condições de vivências, experiências e intercâmbio de ocorrências atuais e/ou anteriores.

As políticas públicas, nem sempre foram voltadas a atender à agricultura do pequeno produtor ou da agricultura familiar, pois 0 atendimento visava outros resultados e o desenvolvimento econômico e industrial, como lema do progresso. Todavia a agricultura em pequena escala ou de subsistência persistiu e começou a ter atenção do governo, principalmente para manter a estabilidade social e permanência do homem do campo no campo.

Assim, políticas e programas governamentais, relacionados a agricultura familiar, começaram a ser incorporadas, por meio de programas, onde o próprio governo passa a ser um consumidor, comprador, dos produtos, fortalecendo estabilidade e viabilidade econômica das atividades da agricultura familiar.

Inúmeros programas de atendimento à agricultura familiar propagaram com a oferta de moradia, estradas, luz, água tratada e inúmeros outros mecanismos que proporcionem melhor condição de permanência do homem do campo com boas condições de infraestrutura e bem-estar social.

\section{RESULTADOS}

4.1. Um olhar para a conjuntura dos produtores rurais no município de Entre Rios do Oeste

Entre Rios do Oeste tem uma área territorial de 120,327 $\mathrm{km}^{2}$. Deste espaço territorial, 3.462 hectares (ha) são ocupados com cultivo de lavoura temporária, 3.644 ha destinados as atividades pecuárias e criação de outros animais, 19 ha estão alocados para a horticultura e floricultura e a pesca ocupa uma área de 14 ha.

A população estimada do município de Entre Rios do Oeste é de 4.357 habitantes. A distribuição desta população quanto à sua localização, embasado em dados de 2010 (IBGE, 2010) está na seguinte ordem: 2.642 residentes na área urbana e 1.284 domiciliados em área rural, em um percentual de proporcionalidade que se mantém numa taxa de urbanização de $67 \%$. (IBGE, 2016).

A população da área rural está distribuída em linhas comunitárias, que em alguns municípios são denominados de localidades e/ou distritos, formalizados em termos de lei. As linhas (povoados expressivos em população, mas distantes da área urbana principal) existentes pelo município e apontadas neste trabalho correspondem: Entorno (compreendem as propriedades próximas, ao entorno da sede municipal, da cidade), Linha Barra Grande, Linha Boa Esperança, Linha Divisa, Linha Dois Irmãos, Linha Fátima, Linha Felicidade, Linha Feliz, Linha Golondrina, Linha São Paulo, Linha Vista Alegre, Linha Vista Alta e a Linha Volta Gaúcha.

Nessas linhas, há associações comunitárias e o objeto de pesquisa será a Associação de Produtores Orgânicos de Entre Rios - APOER, com sua administração instituída e em plena atividade e seus produtores encontram-se nas linhas Golondrina, Vista Alegre, Linha Feliz, Linha Divisa, Volta Gaúcha e Linha Fátima.

As ações dos governos por meio de suas políticas públicas e destas as voltadas para a agricultura e principalmente à agricultura familiar, mesmo com maior dinamismo na relação entre governo/agricultor, tem como objetivo principal atender as expectativas dos agricultores. Os agricultores por sua vez sempre têm novas demandas e necessitam de atenção dos governantes ao atendimento de seus anseios e permanência no campo.

Dessa forma, analisar o desempenho e o cumprimento de objetivos da Administração Pública revela-se indispensável na consolidação de um Estado sério, que exerce suas funções com objetividade e comprometimento, elevando substancialmente sua credibilidade perante a sociedade (ARAÚJO, 2009). Conforme afirma Araújo (2009, p.158), o balanço orçamentário "[...] apresenta as receitas estimadas e as despesas fixadas no orçamento em confronto, respectivamente, com as receitas arrecadadas e com as despesas realizadas" [...].

Analisar tais informações, cruzando planejamentos com projetos efetivamente executados, mostra-se indispensável na avaliação do desempenho de gestões. Para isso, fez-se o levantamento do valor total do orçamento do município de Entre Rios do Oeste e o valor destinado para a agricultura no período de 2013 a 2016 (Tabela 1). Essa perspectiva demonstra as atividades empreendidas na agricultura e os seus limites orçamentários.

$\mathrm{Na}$ Tabela 2, conforme a pesquisa, identificou-se os valores do orçamento para cada política pública destinada a agricultura.

Os valores do orçamento para as políticas públicas da Secretaria da Agricultura apontados são complementados com valores destinados as despesas de manutenção da própria secretaria e com a alocação de um dado valor para a aquisição de área de terra para implantação do parque ecológico (Tabela $3)$.

Identificou-se que apesar do valor repassado para a Secretaria da Agricultura ter diminuído no decorrer dos anos, o valor aportado às políticas públicas aumentou conforme demonstrado na Tabela 03 , o que pode indicar que a prefeitura passou a olhar com mais cuidado o meio rural. 
Como o universo dos agricultores familiares no município de Entre Rios do Oeste compõe-se de 555 unidades, definiu-se por fazer um recorte e entrevistar um grupo de produtores. Para ter um entendimento de como os produtores rurais da agricultura familiar fazem uso das políticas públicas disponibilizadas pela prefeitura municipal, e as percepções destes a respeito das mesmas, fez-se, então, uma pesquisa de campo, entrevistando 26 produtores da agricultura familiar, pertencentes a Associação dos Produtores Orgânicos de Entre Rios do Oeste. (APOER). Os resultados da pesquisa se encontram na Tabela 4.

Fez-se a apropriação da Tabela 5, constando em suas linhas a relação dos produtores em termos de tamanho de sua propriedade da menor para a maior área existente. Em relação as colunas, fez-se a identificação das políticas públicas das mais acessadas na faixa da esquerda para as menos acessadas na parte direita das colunas. Conforme demonstrado na Tabela, todos os produtores fizeram uso de uma ou mais políticas públicas do município. Além das políticas municipais a tabela contém algumas políticas a nível nacional (PAA e PNAE) e uma política estadual (auxílio ao projeto casa rural). Estas políticas constam na relação, pois a técnica e a EMATER auxiliam os produtores para $o$ acesso às mesmas.

Segundo o presidente da APOER, na entrevista realizada com o mesmo, já houve participação do gestor municipal, que se fez presente em algumas reuniões da associação para ouvir as propostas e anseios dos produtores. Em relação à produção, os produtores desenvolvem as seguintes atividades: produção de soja, milho, horticultura, gado leiteiro e seus derivados, suínos, peixes, frango e ovos, panificação turismo rural e produção de mel. Essa diversidade encontrada nas propriedades exige muito empenho e necessidade de mão de obra, seja na própria manutenção das atividades seja para realizar as atividades exigidas para obter bons produtos que possam atender ao mercado comprador.

Entre as dificuldades ressaltadas pelos produtores rurais, encontram-se inúmeras, mas cabe destaque a algumas que não estão ao alcance dos gestores municipais públicos: melhor remuneração para a produção de leite orgânico, incentivo na aquisição dos insumos para a produção de leite por ter períodos que é pouco rentável. Dificuldade de mão de obra temporária decorrente da necessidade de efetivar todas as atividades não possíveis de serem realizadas somente com a mão de obra familiar para atender a toda demanda para a condição do esperado pelos proprietários. Existe a disponibilidade de um trator Yamaha com enxada rotativa que atende a todos produtores da APOER, facilitando muito as atividades mais pesadas no preparo do solo, mesmo assim carece de mais cuidados, mão de obra, para o pleno andamento das atividades das propriedades. Falta de mercado consumidor, alta intensidade de chuva ou a falta dela também foi relacionado como problemas as atividades praticadas, pois podem prejudicar, e pôr em risco todo uma cultura de hortaliças, as pastagens pela falta de chuva e diminuir a produção de leite e dificultar no preparo do solo para a produção das hortaliças.

Tabela 1. Orçamento Município de Entre Rios do Oeste (2013/2016).

Table 1. Budget Municipality of Entre Rios do Oeste (2013/2016).

\begin{tabular}{|c|c|c|c|c|c|}
\hline & & 2013 & 2014 & 2015 & 2016 \\
\hline \multirow{3}{*}{ S } & Orçamento total & 17.600 .000 & 23.172 .350 & 24.850 .000 & 29.700 .000 \\
\hline & Valores Sec. Agri & 1.462 .480 & 1.326 .510 & 1.425 .000 & 1.637 .700 \\
\hline & $\%$ Sec. Agricult. & 8,31 & 5,72 & 5,73 & 5,51 \\
\hline
\end{tabular}

Fonte: Quadro de Detalhamento da Despesa - Portal da Transparência Município de Entre Rios do Oeste

Tabela 2. Valores em Reais (R\$) do Orçamento Municipal para as políticas públicas da Secretaria da Agricultura.

Table 2. Values in Reals (R \$) of the Municipal Budget for the public policies of the Secretariat of Agriculture. Repasses do município para as políticas públicas da Secretaria da Agricultura (2013-2016)

\begin{tabular}{|c|c|c|c|c|}
\hline Políticas Públicas & 2013 & 2014 & 2015 & 2016 \\
\hline Manejo de dejetos animais & 10.000 & 10.000 & 14.000 & 30.000 \\
\hline Manutenção e conservação de abastecedouros comunitários & 10.000 & 20.000 & 10.000 & 15.000 \\
\hline Manutenção do viveiro de mudas & 1.000 & 3.000 & 2.000 & 2.000 \\
\hline Manutenção do Programa de Educação Ambiental & 10.000 & 7.000 & 2.000 & 1.500 \\
\hline Manutenção do Programa Cultivando Água Boa (Em parceria com a Itaipu Binacional) & 222.000 & 277.000 & 364.300 & 390.000 \\
\hline Análise de Solos & 3.865 & 6.600 & 5.000 & 4.000 \\
\hline Distribuição de Esterco Líquido & 30.000 & 40.000 & 40.000 & 62.000 \\
\hline Fomento à cama de aviário & 45.000 & 34.000 & 130.000 & \\
\hline Incentivo a agricultura orgânica & 13.000 & 15.000 & 10.000 & 15.000 \\
\hline Incentivo a apicultura & 10.000 & 10.000 & 5.000 & 15.000 \\
\hline Melhoria genética do gado leiteiro & 52.000 & 59.000 & 60.000 & 76.000 \\
\hline Melhoria genética do rebanho suíno & 48.000 & 48.000 & 45.000 & 55.000 \\
\hline Apoio ao desenvolvimento da piscicultura & 10.300 & 25.000 & 54.000 & 80.000 \\
\hline Controle da formiga & 1.000 & 10.000 & 8.000 & 10.000 \\
\hline Assistência técnica agropecuária & 116.215 & 131.600 & 128.000 & 268.000 \\
\hline Aplicação de calcário & & 10.000 & 10.000 & 80.000 \\
\hline Fomento a adubação verde (distribuição de aveia) & & 28.100 & 32.000 & 35.000 \\
\hline Controle da brucelose e tuberculose & & 24.000 & 48.000 & 52.000 \\
\hline Manutenção e remodelação da Feira do produtor & & & 19.000 & \\
\hline Auxílio na aquisição de ordenhadeiras e resfriadores a produtores rurais & & & 30.000 & \\
\hline Amparo ao pequeno produtor rural & & & 30.000 & \\
\hline Total & 582.380 & 758.300 & 1.046 .300 & 1.190 .500 \\
\hline
\end{tabular}

Fonte: Quadro de Detalhamento da Despesa - Portal da Transparência Município de Entre Rios do Oeste. 
Tabela 3. Destinação do Orçamento na Secretaria de Agricultura.

Table 3. Allocation of the Budget in the Secretariat of Agriculture

\begin{tabular}{ccccc}
\hline & 2013 & 2014 & 2015 & 2016 \\
\hline Orçamento total para Secretaria da Agricultura & 1.462 .480 & 1.326 .510 & 1.425 .000 & 1.637 .700 \\
Valores repassados as Políticas Públicas & 582.380 & 758.300 & 1.046 .300 & 1.190 .500 \\
Valores em \% & $40 \%$ & $57 \%$ & $73 \%$ & $72 \%$ \\
Valores Manutenção da Secretaria e Aquisição de área de terra & 880.200 & 568.210 & 378.700 & 447.200 \\
para o Parque Ecológico & $60 \%$ & $43 \%$ & $27 \%$ & $28 \%$ \\
\hline Valores em \% & $60 \%$ &
\end{tabular}

Fonte: Quadro de Detalhamento da Despesa - Portal da Transparência Município de Entre Rios do Oeste.

Tabela 4. Políticas Públicas acessadas pelos produtores associados a APOER.

Table 4. Public policies accessed by producers associated with APOER.

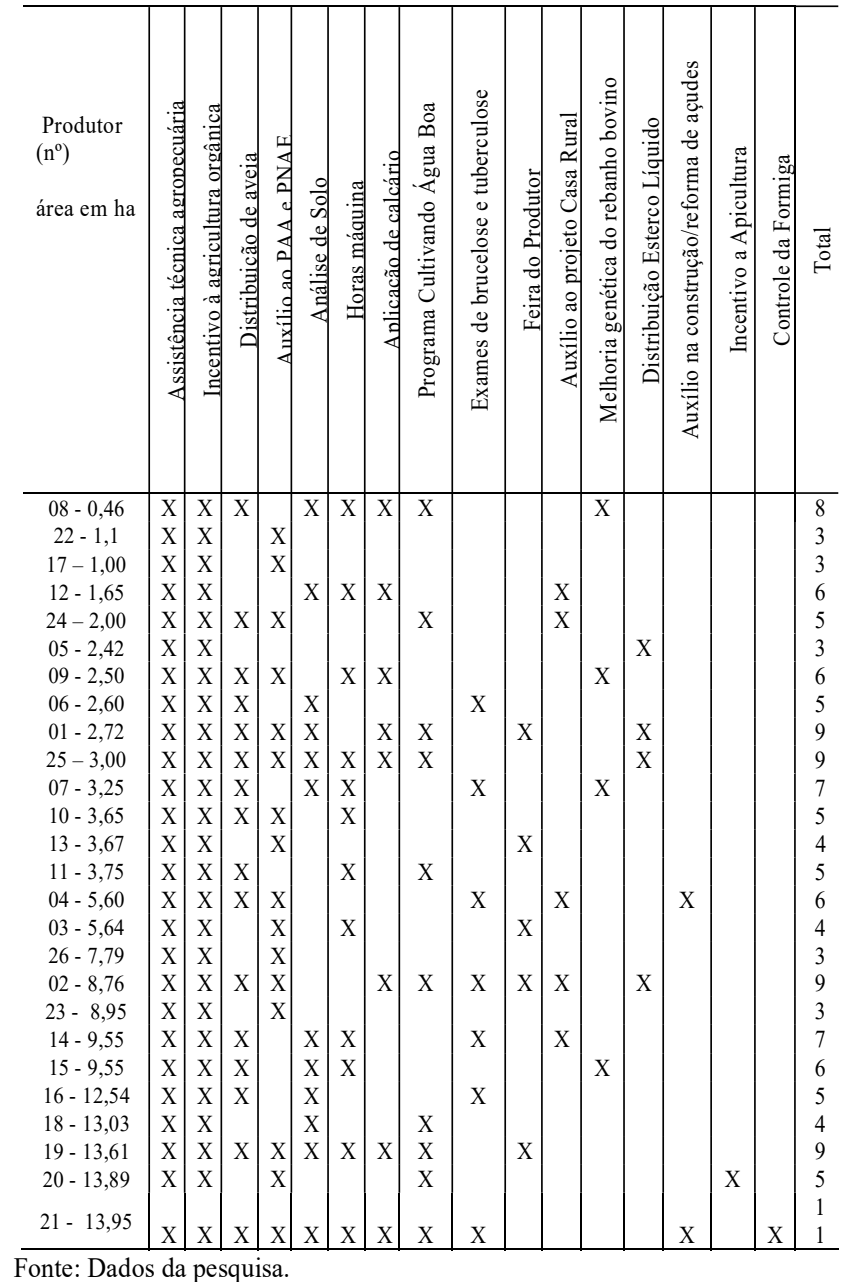

O aspecto de escoamento da produção é uma dificuldade abordada por vários produtores. Segundo Buainain (2006), na região Sul do Brasil mais de $70 \%$ dos agricultores familiares vende mais de $50 \%$ de sua produção. Isso demonstra a importância do comércio para esses agricultores.

Mesmo que os relatos sejam de forma exclamativa quanto às dificuldades na atividade, o que é normal diante da quantidade de trabalho que demanda uma propriedade inclinada a produção de hortaliças e produtos orgânicos, os produtores demonstram uma enorme satisfação e orgulho de sua propriedade e de suas atividades quando relatam sobre as mesmas. A possibilidade de consumo de produtos naturais e saudáveis a família e aos consumidores/clientes para manter uma condição de vida saudável e de bem-estar pelo dinamismo da propriedade e estabilidade econômica, com um bom padrão de vida. A possibilidade de dar oportunidade aos filhos como uma alternativa de vida e ter sua própria atividade faz parte de inúmeros relatos.

Outro aspecto positivo refere-se à assistência técnica prestada pela técnica da BIOLABORE. Identificou-se que vários produtores passaram a utilizar a agricultura orgânica em detrimento da agricultura convencional. Esse trabalho de mudança teve a participação e assistência da técnica. A redução do agrotóxico se faz presente em todos os 26 relatos dos produtores (100\%), e segundo os mesmos a diminuição foi em torno de 70 a $80 \%$ no uso de agrotóxicos mediante novas práticas de cultivo e condição das atividades agrícolas.

4.2. Diálogo entre a teoria ator orientado, políticas públicas e os atores da agricultura familiar

Este tópico tem por objetivo discutir os resultados coletados na pesquisa empírica conectando-os à teoria utilizada para compreender os processos observados. Nele, procura-se demonstrar como a Teoria Ator Orientado ou Perspectiva Orientada ao Ator (POA), pode contribuir para o entendimento das políticas públicas e dos atores envolvidos.

\subsubsection{Arenas: APOER e Produtores versus Poder Público}

Segundo Long (2002), a análise deve sempre focar nas práticas de intervenção, porque, assim, é possível entender as formas de interação, os procedimentos, as estratégias, tipos de discursos e as categorias culturais dos atores e agentes interventores envolvidos.

Uma das modificações/intervenções mais significativas que se observou na pesquisa de campo refere-se à transição da agricultura convencional para a agricultura orgânica, através de política de incentivo específica para esse fim. Os agricultores relataram que o processo de transição foi trabalhoso, e feito paulatinamente, necessitando de entendimento e incorporação desse novo procedimento, técnica, em virtude do longo tempo de uso de agrotóxicos estar muito presente nas propriedades.

Identificou-se que nesse processo formou-se uma arena, que Long (2001) chama de 'campos de batalha do conhecimento'. Segundo o autor é o espaço em que os atores são confrontados com as experiências, interesses e valores uns dos outros.

Os agricultores afirmaram que com os novos procedimentos de cultivo, com redução ou sem o uso de agrotóxicos, houve mudanças nas propriedades, pois tiveram a necessidade de incorporar novo aprendizados, uso mais intenso de assistência técnica e troca de experiências entre os produtores. Entretanto, as vantagens galgadas e os contínuos avanços no aprimoramento desta forma de cultivo, sem agrotóxico ou com o mínimo possível do mesmo, são de muito 
valor e reconhecimento por parte dos produtores, entre eles e para seus clientes, mercado, pelo novo procedimento de cultivo. As mudanças de hábitos nas propriedades são notáveis pela postura dos produtores em aceitar orientações técnicas e intercâmbio de experiências entre eles, compartilhando suas vivências para o bem comum. Segundo Sarandon (2009), a agroecologia, pelas características da agricultura familiar tem o potencial de contribuir para diminuir problemas atuais da agricultura: o uso crescente de agrotóxicos, degradação dos recursos ambientais, impacto negativo sobre a saúde dos agricultores, contaminação de alimentos e meio ambiente, problemas esses citados pela totalidade dos entrevistados.

Nessa arena, também se encontram os dilemas e desafios institucionalmente construídos como: as políticas públicas, ONGs, pesquisas acadêmicas e de órgãos de fomento, dentre outros que fazem parte do debate (LONG, 2002). No caso da pesquisa, os atores são: a prefeitura (órgão público) com suas políticas públicas, Itaipu (órgão público de âmbito federal) parceira da Prefeitura, o técnico da BIOLABORE (empresa de assistência técnica, parceira da ITAIPU) e a APOER.

Foi identificado nas entrevistas que existem discussões, negociações entre os produtores e a técnica agroecológica, proporcionando confiança à incorporação de novas práticas agrícolas de cultivo e de relacionamento entre os produtores com novos saberes e adesão à agricultura orgânica. Estes acontecimentos registrados com os produtores são considerados por Long (2002) quando aponta o conceito de campos de batalha, onde o conhecimento reforça as ocorrências de mudanças sociais nos projetos de desenvolvimento rural, fato esse verificado in locu através do projeto de incentivo à agricultura orgânica que provocou mutações no aspecto produtivo e no conhecimento dos produtores além do próprio relacionamento comunitário entre estes pares mais integrados e participativos.

A principal mudança foi na mentalidade dos produtores. Segundo os mesmos, as novas formas de cultivo com a redução imediata do uso do agrotóxico, foi importante, pois permitiu que passassem a consumir e vender alimentos naturais, mantendo uma condição de vida mais saudável, com benefícios desde a manutenção das propriedades orgânicas do solo, aos próprios produtores e aos consumidores, proporcionando um benefício social em rede interligada.

Quando o produtor desenvolve de forma integral as práticas agrícolas sem uso de agrotóxico pode obter uma certificação oficial pelo Instituto de Tecnologia do Paraná TECPAR, caracterizando a propriedade livre de agrotóxicos. A garantia de produção natural, pela forma de cultivo e com esta referência de certificação, é motivo de orgulho e satisfação de um dos agricultores orgânicos associado a APOER, portador deste mérito, e proporciona interesse pelos seus produtos por inúmeros estabelecimentos consumidores, ou seja, amplia o mercado para a venda de seus produtos.

Em visitas realizadas a produtores juntamente com a técnica da BIOLABORE, apreciou-se os processos da assistência técnica. Foi notória a troca de conhecimentos entre o produtor e a técnica. Num caso em particular, havia problema de pulgões na plantação de morangos de determinado produtor, desencadeando um debate sobre como resolver a questão dos pulgões e as diversas possibilidades de acabar, controlar a praga. O confronto de alternativas, informações, vivências e análise dos possíveis resultados foram levantados e considerados tanto pelo produtor quanto pela técnica da Biolabore. Por fim, com muito diálogo e avaliações das alternativas, chegou-se a um consenso. Assim a teoria de Long foi praticada pelos atores (produtor e técnica) quando confrontados com diferentes experiências para buscar resolver um problema específico e obter o melhor resultado possível ao caso.

Alguns produtores têm diversidade de atividades em suas propriedades, com produtos agrícola e animal, no caso de suínos e bovinos, para produção de leite. Um dos produtores passou a usar a homeopatia ${ }^{1}$ como uma terapia de saneamento aos seus animais, com grandes resultados. Esse procedimento despertou interesse da técnica da Biolabore que passou a estudar essa técnica e convencida desse método, começou a repassar para outros produtores, o que demonstra novamente a boa prática, uso, da teoria de Long. Diante dos resultados positivos deste procedimento, a técnica orienta e dissemina este conhecimento obtido inicialmente de um produtor, aos demais, com uso de medicação natural no rebanho bovino e/ou suíno e com bons resultados. Pôde-se confirmar este procedimento diretamente com os produtores que passaram a fazer o uso da homeopatia em seus rebanhos e da conquista de resultados satisfatórios com esse procedimento natural.

A troca de experiências é um procedimento constante e contínuo entre os atores, e quando da reunião da APOER, realizada em outubro, os produtores discutiram várias formas diferentes de produzir, e os saberes foram sendo apresentados e reapresentados, formando uma teia de conhecimentos. Nesta reunião da APOER, a aplicação dos conceitos foi constatada também na política pública (PNAE). Nessa reunião, os produtores debateram a proposta do PNAE do ano de 2017, juntamente com a nutricionista do município, representando, o poder executivo, estatal, e constatou-se um amplo debate entre os diversos participantes na construção da proposta, o que caracteriza mais uma vez o uso da teoria de Long (campos de batalha de conhecimento) no uso de discussão ao bem de todos.

A mediadora da reunião da APOER, a técnica da BIOLABORE, relacionou os itens e preços sugeridos para a programação do próximo ano. Os produtores reivindicaram a inclusão de mais produtos na proposta e depois de algumas discussões chegaram a um acordo, incluindo os produtos sugeridos. A nutricionista relatou e constatou que alguns produtos constantes na proposta do PNAE de 2016 não foram entregues necessitando a compra dos mesmos em outros locais, municípios para atender a demanda local. Os produtores argumentaram o não cumprimento da proposta devido a ocorrência da sazonalidade e condições climáticas desfavoráveis. Todavia ao término da reunião, ficou acordado um valor de $\mathrm{R} \$ 42.000,00$ para 2017, ou seja, um incremento de $\mathrm{R} \$ 10.000,00$ a mais ao ano anterior de 2016.

Esse valor total da proposta, será dividido entre os treze participantes (50\%), enquadrados nas condições necessárias e que se comprometeram a fornecer os produtos para a prefeitura. Cabe ressaltar que os produtos orgânicos têm um

\footnotetext{
${ }^{1}$ São medicamentos preparados a partir de substâncias que são submetidas a triturações sucessivas ou diluições seguidas de sucussão, ou outra forma de agitação ritmada, com finalidade preventiva ou curativa a serem administrados conforme a terapêutica homeopática, homotoxicológica ou antroposófica. O

medicamento homeopático pode ser derivado de plantas, animais ou minerais O farmacêutico homeopata transforma essas substâncias em medicamentos homeopáticos através de uma técnica especial chamada dinamização. (ANVISA, 2016)
} 
custo de produção maior que os produtos produzidos de forma tradicional, dada as formas de cultivo e técnicas empregadas que demandam maior atenção e cuidados onerando sua produção. Assim, os produtores não obtêm renda suficiente, ou seja, a viabilidade do aspecto econômico da propriedade, com produção somente para os programas federais (PAA e PNAE) não é suficiente para manter a propriedade. Estes produtores também sentem dificuldades em colocar seu produto no mercado, por terem um custo mais elevado do que o tradicional, necessitando assim disponibilizar seus produtos a um preço mais elevado no mercado e nem sempre percebido pelos consumidores.

A maior parte dos entrevistados relatou que outro problema para os orgânicos são os canais de comercialização para escoamento da produção. Segundo Buainain (2006), na região Sul do Brasil mais de $70 \%$ dos agricultores familiares vende mais de $50 \%$ de sua produção. Isso demonstra a importância do comércio para esses agricultores, todavia falta uma valoração maior a estes produtos.

Segundo Abramovay (2005), a organização de produtores em associações é um exemplo importante de união, possibilitando aos produtores entrarem no comércio local. No caso dos orgânicos, universo da pesquisa, a APOER (Associação dos Produtores Orgânicos de Entre Rios do Oeste) é o órgão que dá suporte aos produtores, e a importância da associação se faz sentir, pois através dela a Prefeitura pode repassar recursos e incentivar a produção agroecológica no município. Com o amparo da APOER, a prefeitura disponibilizou um espaço para a Feira do Produtor, para a venda de produtos agroecológicos aos munícipes que permite diversificar a fonte de renda por meio de novos clientes dos produtores orgânicos do município.

A participação na reunião permitiu a constatação de que os produtores não são destinatários passivos de intervenções, mas sim participantes ativos, com capacidade de criar estratégias através de suas interações sociais e institucionais (LONG, 2007). Na reunião para tratar da construção do projeto 2017 para o PNAE, a intervenção junto à essa política pública e de como os diferentes atores envolvidos agem nessa construção, percebeu-se a forma interativa entre os atores com paridade de valores e comprometimento ao tema abordado exercendo sua capacidade de agência, um dos conceitos chave da Teoria Ator Orientado. A "agência humana" (capacidade de atuar, entender, processar suas experiências) é identificada então, nas relações mútuas de atores "internos" e "externos" que entram em contato em "campos de batalha de conhecimento".

O estabelecimento e participação dos produtores rurais, na determinação das suas propostas pode ser identificada na política pública de Manutenção da Feira do Produtor, onde os produtores orgânicos, que vendem sua produção, nesta feira, através da associação, para o ano de 2017, serão atendidos com refrigeradores para conservação dos produtos, permitindo maior durabilidade e perdas de produtos, além de um ar condicionado para o ambiente da feira, proporcionando maior conforto no ambiente de trabalho.

Segundo a Teoria Ator Orientado serão dentro das arenas, espaços onde há práticas e valores de domínios diferentes que devem ser feitos esforços para resolver os interesses dos atores (Long, 2001). Quer dizer, as autoridades devem dialogar com os diferentes atores sociais para a construção e oferta das políticas públicas. Para $38 \%$ dos produtores entrevistados, a prefeitura precisa dialogar mais com os produtores na construção das políticas públicas e oferecer mais incentivo para a agricultura.

O restante dos entrevistados, $62 \%$, demonstrou satisfação quanto às políticas públicas oferecidas. Cabe mais um reforço ao interesse em reivindicar, caso necessário, de forma formal a solicitação de acesso as políticas de seu interesse.

\subsubsection{Conceito de agência: capacidades dos atores da APOER}

O conceito de agência atribui ao ator individual a capacidade de processar, ordenar e sistematizar suas experiências sociais. A agência é a capacidade de conhecer e atuar, de modo que as ações e as reflexões constituam práticas sociais que impactam ou influenciam nas ações e interpretações, tanto próprias como de outros, e se compõe de uma mescla de elementos sociais, culturais e materiais. (LONG, 2007; KRUEL, 2010, p.7)

Identificou-se nos produtores orgânicos associados a APOER, uma percepção dos mesmos como atores. Eles se enxergam como atores ativos que elaboram, testam e modificam quando necessário suas práticas e projetos, fugindo do estereótipo de agricultor que só replica técnicas agrícolas em sua propriedade.

Por exemplo, na reunião da APOER, constatou-se que para definição do projeto PNAE 2017, os produtores orgânicos primeiramente se manifestaram e debateram sobre práticas da agricultura, dentro da própria associação que é um espaço de debate e eles têm essa abertura. No segundo momento, houve a elaboração da proposta com a participação da técnica e a nutricionista, representando neste momento a prefeitura. Neste espaço e momento constatou-se a capacidade de agência, com a participação igualitária para discutir os produtos a serem oferecidos, o estabelecimento do preço de venda dos produtos diante das condições e limitações de produção de cada produto, as condições de oferta dos produtos para o consumo, a preocupação levantada por parte da nutricionista para o atendimento das propostas em relação a oferta dos produtos que deve ser atendida pelos produtores. Essa condição de produzir e garantir a entrega dos produtos foi cobrada por parte dos próprios produtores entre si, para atender ao firmado nesta proposta, honrando o estabelecido por parte da associação de produtores orgânicos, já que alguns não atenderam ao contido na proposta de 2016. Nesse momento, percebe-se a atenção em resolver seus problemas, intervindo no fluxo de eventos sociais ao seu redor e monitorando suas ações e do restante do grupo no encontro de manter boa relação entre todos os atores e viabilidade desta política pública ao compromisso comum e benefício social.

Em outra política pública (manutenção da Feira do Produtor), eles também exerceram sua agência, ao conquistar um espaço junto a prefeitura para comercializar os produtos orgânicos. E segundo os próprios produtores, para 2017, a solicitação que fizeram junto a Prefeitura, para aquisição de refrigeradores para conservar os produtos por um período maior devido os fatos dos mesmos serem perecíveis e ar condicionado para manter um ambiente de trabalho mais adequado, foi atendida pelo poder municipal e deverá fazer parte das atividades em 2017

Quanto as outras políticas públicas, os dez produtores (38\%) que apontaram a necessidade de mais diálogo por parte do Poder Público para a elaboração das mesmas, identificouse que não se sentem como atores capazes de intervir no seu entorno quanto às políticas públicas. Mas todo os participantes 
afirmaram que as políticas beneficiam o produtor, pois fornecem vários insumos (calcário, aveia) e serviços (como análise de solo, por exemplo) que diminuem o custo da produção, distribuição de esterco nas lavouras, disponibilidade de máquinas para efetivação de diversos serviços nas propriedades de forma gratuita ou subsidiada.

\subsubsection{Heterogeneidade no meio rural}

Segundo Long $(2007,2001)$, a Teoria Ator Orientado contribui para analisar as heterogeneidades apresentadas no espaço rural, pois o foco é dado em como os atores, a partir de seus recursos (naturais, políticas públicas, redes sociais, mercados, e de outras relações entre rural e urbano), definem e operacionalizam seus objetivos e práticas.

A agricultura familiar é heterogênea, segundo Buainain (2006) e a mesma possui esse caráter devido principalmente a fatores culturais, ambientais, sociais e econômicos. Nesse meio, encontram-se produtores que vivem pouco acima da linha da pobreza até os grandes proprietários de terras, que atuam em mercados locais até mercados internacionais, que utilizam os recursos de formas diferentes, com heranças culturais diferentes, enfim, possuem um caráter multifacetado. (BUAINAIN, 2006). Nesse ambiente diversificado, devem se desenvolver as políticas públicas para a agricultura, e é por causa dessa diversidade que a formulação de políticas públicas para o meio rural se torna um desafio.

Trazendo essa realidade para o contexto da pesquisa, as políticas voltadas exclusivamente para os produtores orgânicos (incentivo à agricultura orgânica, manutenção da Feira do Produtor e políticas de apoio ao PAA e PNAE) foram construídas pelos produtores e prefeitura. Isso se confirmou nas entrevistas, pois os produtores através da associação passaram a reivindicar seu espaço e oportunidades para os produtos orgânicos. Assim, atualmente, eles conseguem vender parte de sua produção, tanto na Feira, quanto para os órgãos públicos, por um valor mais adequado para o produto orgânico (devido seus custos mais elevados e menor produção) e tem outras políticas de incentivo para manter-se no campo. Conforme os produtores, ainda não é a solução ideal para a agricultura orgânica, mas a prefeitura vem contribuindo de alguma forma para o escoamento da produção e aumento da produção orgânica.

A assistência técnica fornecida pela BIOLABORE é exclusiva para os produtores orgânicos, sendo assim, eles possuem assistência mais constante, pois é um grupo de 26 produtores orgânicos $(100 \%)$, permitindo que a técnica tenha mais tempo para atendê-los. Quanto as outras políticas, elas são mais generalistas, pois devem atender a todos os agricultores do município. Identificou-se na pesquisa, que os produtores orgânicos também têm acesso a essas políticas e todos já fizeram uso de uma ou mais delas em algum momento.

\subsubsection{Ação Social, Culturas e Significados da APOER}

Long (2002) diz que um dos conceitos centrais da análise ator-orientado são as culturas e significados. Esses significados, valores e interpretações não são construídos apenas no aspecto cultural, eles são aplicados, replicados e reinterpretados de acordo com as mudanças e comportamentos, o que acaba por gerar novos padrões culturais. Através da pesquisa identificaram-se alguns elementos que podem indicar a construção um novo padrão cultural que ocorre como resultado da adesão de produtores rurais à agricultura orgânica e à APOER.

Esses atores (os produtores orgânicos) tomam decisões baseadas em preferência de valores e conhecimentos disponíveis, recursos e relacionamentos (LONG,2001). Quando questionados sobre o porquê da mudança, vários afirmaram que se preocupam com os problemas ambientais decorrentes da agricultura. Outros afirmaram que buscavam melhor qualidade de vida e alimentos mais saudáveis, e por fim, há argumentos relacionados à obtenção de renda extra para se manter e manter os filhos no campo.

Esse novo padrão cultural se tornou uma ação social, pois se efetivou dentro de uma rede curta de relações (Prefeitura, Biolabore, APOER e produtores orgânicos) além de se estender para redes mais longas conectando-se ao discurso mais amplo de sustentabilidade, desenvolvimento sustentável e agroecologia. Long (2002) afirma que a ação social nunca é individual. A ação social se forma pela rotina e pelas práticas organizativas exploratórias limitadas por convenções sociais, valores e relações de poder. Os produtores construíram um projeto social negociado a partir dos projetos individuais de cada um dos atores. Com esse projeto maior, conseguem negociar junto a essas arenas maiores, como a prefeitura, nesse caso, atendendo aos interesses da comunidade como um todo frente ao benefício comum auferido.

\subsubsection{Interface Social}

Segundo Long (2002), a interface social permite o entendimento de como ocorrem os vários embates relativos aos processos de intervenção. Observar as interfaces possibilita perceber como os atores formam suas "visões de mundo" e como se transformam no processo. É na interface que os atores se expõem e explicitam suas posições políticas e ideológicas, que os problemas e os resultados são apresentados, discutidos e mediados, e os acordos são forjados e desfeitos. (ALVES, 2008)

Conforme relatos dos produtores, a transição da agricultura convencional para a agricultura orgânica é um processo lento e trabalhoso. Dessa forma, para conquistar espaço para esse grupo junto ao Poder Público, primeiramente, os atores tiveram que se organizar em uma associação, a APOER. Essa formatação jurídica deu mais força, e permitiu que produtores, através da associação tivessem suas reivindicações atendidas, na forma de políticas públicas para esse público específico.

A utilização da noção de interface também foi identificada na relação da técnica da BIOLABORE, que se depara com o conflito entre seus próprios interesses, os interesses do grupo da APOER e os interesses da instituição a qual pertence. Devido aos interesses e objetivos muitas vezes diferentes, o que ocorre na situação de interface, entre a técnica e o agricultor, é a possibilidade de transformações nas percepções e metas de ambos. E isso se confirmou, pois conforme a técnica, sempre há uma troca de conhecimentos entre ela e os produtores orgânicos.

$\mathrm{Na}$ Teoria Ator Orientado, Long (2002) explica a interface como conflitos culturais, quer dizer, os indivíduos ao expressaram suas opiniões pessoais, demonstram sua cultura implícita. A partir disso, pode-se compreender como os produtores com suas práticas, experiências, visão de mundo, optaram por fazer a transição para uma agricultura mais sustentável. Segundo os relatos, a possibilidade de consumir produtos mais saudáveis pela família, a diversidade de produtos de qualidade, o bem-estar em função da diminuição 
dos agrotóxicos e a possibilidade de mais uma renda extra, expressam as novas impressões que os mesmos têm a respeito da agricultura orgânica.

O próprio saber tradicional evoluiu e continua evoluindo através de novas experiências, informações, técnicas, mas isso, além de promover a heterogeneidade na agricultura, permite que se estabeleça uma interface mais dinâmica, uma relação entre as demandas culturais e econômicas dos agricultores e os recursos disponíveis no meio ambiente, ou seja, é um novo estilo de agricultura (os saberes tradicionais) que se agregam para a produção orgânica. Outra situação em que a noção de interface aparece é na relação dos produtores com o órgão público, seja na reivindicação e/ou na participação no estabelecimento de novas políticas públicas, seja na apropriação das políticas existentes, no encontro de melhores condições de vida própria e da comunidade e sua permanência e de seus descendentes no campo.

Nesse processo, os atores, agricultores familiares associados da APOER, passam a competir não somente com os novos atores externos, mas também com a capacidade de agência de agricultores e parceiros frente às novas possibilidades abertas pelas políticas públicas, pelo mercado globalizado, uma nova interface. Todos esses atores se inserem em diversas redes de interesses que interagem mediante formas dinâmicas nas interfaces criadas pelos projetos que aumentam e tornam mais complexa a tarefa dos implantadores de tais iniciativas (ALVES, 2008).

As políticas públicas voltadas exclusivamente aos produtores orgânicos (recorte dessa pesquisa), segundo as entrevistas, estão atendendo, no sentido de alavancar a produção orgânica. Alguns gargalos se fazem presentes ainda, relacionados a escoamento da produção para centros de consumo maiores. Neste sentido, estudos e providências estão sendo analisados, seja no meio de transporte a ser adquirido, seja nos pontos de venda dos produtos, e segundo a técnica e informação dos próprios produtores, contatos estão em andamento com a Cooperativa da Agricultura Familiar e Solidária do Oeste do Paraná (COAFASO) para venda da produção excedente.

Conforme a pesquisa e os relatos dos produtores associados a APOER, através da associação, eles têm mais força para reivindicar apoio dos órgãos públicos. Dessa forma, conseguem também atuar em diversos mercados, como o mercado local através da Feira do Produtor ou diretamente aos consumidores, além das políticas públicas do PAA e PNAE. O andamento das negociações com a COAFASO, trata-se de nova perspectiva e possibilidade de venda de boa parte da produção.

$\mathrm{Na}$ agricultura de base ecológica a diversificação da produção e da comercialização são elementos importantes para a sustentabilidade econômica, ambiental e social (AHRENS, et al., 2013; BARBOSA et al., 2013). Nesse sentido, constatou-se uma preocupação da técnica para introduzir novas práticas de cultivo com vistas a diminuir custos, buscar maior produtividade amenizando os problemas de produção bem como perdas por diversos fatores, entre eles, os climáticos com sistemas de irrigação e cobertura com tela para as culturas mais suscetíveis. A busca de novos cultivos para diversificar a renda é uma preocupação constante dos produtores e da técnica, para proporcionar maiores fontes ou diversidade nas fontes de renda.
A partir das políticas públicas de incentivo à agricultura orgânica, segundo os produtores, eles passaram a produzir com mais qualidade, sem agrotóxicos, permitindo uma renda extra em sua propriedade. Quando inquiridos sobre a permanência no campo, todos afirmaram que a atividade orgânica contribuiu para isso. Quando analisada a Tabela 04, com respeito as políticas públicas dos associados da APOER, há uma significativa apropriação dos benefícios de todas políticas. Todos tiveram acesso a assistência técnica e consequentemente, as demais políticas que podem ser aplicadas às condições de suas atividades e interesses. Isto caracteriza que a integração dos produtores com um assessoramento técnico permite maiores benefícios aos mesmos e a municipalidade como um todo.

Segundo Long (2001), ainda que os agentes das políticas públicas se proponham a "escutar" o conhecimento local dos agricultores e a desenvolver estratégias alternativas desde baixo, ainda continuará existindo a contradição de que são agentes externos que têm a tarefa de fortalecer o balanço de forças na direção dos interesses locais. (DEPONTI, 2010). Significa dizer que as políticas públicas não devem ser projetos com limites no espaço e tempo, mas devem ser construídas por todos os agentes considerando as estratégias, práticas, motivações dos atores locais, pois isso constitui sua gênese.

Diante do apontado neste artigo, cabe destacar a importância das práticas da agricultura orgânica no município, pois já representa $43 \%$ da renda dos produtores associados a APOER. Este referencial é de relevada conotação, diante das mudanças exigidas para a efetivação desta prática de cultivo, mas com forte determinação e mudança do modelo mental de trabalho, já em uso por parcela importante destes produtores. A disseminação desta prática é um passo avançado para que todos se integrem a esse novo modelo de produção dentro de suas condições e disponibilidade de recursos e de mão de obra, que exige mais neste aspecto.

Avanços ainda se fazem necessários, e um aspecto importante é que a municipalidade deve buscar entender o mundo de vida dos locais, pois as alternativas e soluções estão nos seus estilos de vida, formas de vivência e na sua valorização. (DEPONTI, 2010). As políticas públicas do município estão sendo acessadas pelos produtores e conforme os mesmos, contribuem para sua fixação no campo, mas quanto mais o órgão público se debruçar sobre os atores, suas práticas, vivências e objetivos, considerando a heterogeneidade do campo, melhores serão as políticas para desenvolvimento no meio rural.

\section{CONCLUSÕES}

Este trabalho apresentou um diagnóstico das políticas públicas do município de Entre Rios do Oeste - PR, que abarcasse tanto as dificuldades como os benefícios advindos destas políticas e como os beneficiários (agricultores familiares) estão percebendo e recebendo as mesmas a luz da Teoria Ator Orientado, buscando responder o problema de pesquisa apresentado.

No geral, identificou-se que as ações municipais relacionadas as políticas públicas buscam uma perspectiva orientada aos atores conforme a teoria de Long. A perspectiva orientada aos atores parte do pressuposto de que diferentes produtores definem e operacionalizam seus objetivos e práticas de gerenciamento agrícola com base em diferentes critérios, interesses, experiências e perspectivas. E no trabalho, 
pode-se concluir que os produtores foram contemplados pelas diferentes políticas públicas atendendo alguns dos objetivos, interesses e expectativas dos mesmos conforme os relatos.

A identificação das características que possam ser potencializadas enquanto alternativas de desenvolvimento local, e no caso dos agricultores orgânicos de Entre Rios do Oeste, relacionada a agricultura convencional para uma agricultura orgânica, tende a demonstrar a busca por um padrão de desenvolvimento sustentável, em novas posturas e comportamento mental dos produtores; com políticas públicas voltadas a essa perspectiva, principalmente na área da divulgação e comercialização dos produtos orgânicos.

Do ponto de vista de estudos futuros, destaca-se a possibilidade de comparar políticas públicas para a agricultura orgânica em diferentes municípios, para verificar como as mesmas são construídas e implementadas junto aos atores beneficiários, além de um estudo sobre os mecanismos que podem ser implantados para o fortalecimento das políticas públicas. Outro estudo seria a identificação das dificuldades e potencialidades relacionadas aos custos de produção nas atividades da agricultura orgânica, como potencial de novos empreendimentos e valoração a esta atividade sustentável.

\section{REFERENCIAS}

ABRAMOVAY, R. MAGALHÃES, R. SCHRODER, M. Agricultura Familiar entre o Setor e o Território. São Paulo. 2005. Disponível em:< http://www.oikonomika .com.br/artigos agricultura_familiar_entre_o_setor_e_o_territorio.pdf $>$ Acesso em: 08 de out 2016.

Uma nova extensão rural para a agricultura familiar. In: SEMINÁRIO NACIONAL DE ASSISTÊNCIA TÉCNICA E EXTENSÃO RURAL, 1., 1997, Brasília. Anais... Brasília: PNUD, 1997.

AHRENS, D.C.; MILLÉO, R.D.S.; ROMMEL, C.C.; COMIRAN, F. Diversificação sustentável da produção e renda: o estudo de caso de uma família de agricultores de base ecológica. Resumos do I Congresso Paranaense de Agroecologia - Pinhais/PR - 29 a 30/05/2014

ALVES, A. F. Do Desenho a Implementação de projetos de desenvolvimento rural sustentável: interfaces e negociações no projeto vida na roça (Paraná). 2008. 234, p. Tese. UFSC. Florianópolis. 2008.

ALTIERI, M. Agroecologia: a dinâmica produtiva da agricultura sustentável. Porto Alegre: Universidade/UFRGS, 1998. 110p.

ANVISA - Agência Nacional de Vigilância Sanitária. Disponível em: http:/www.anvisa.gov.br/ medicamentos /homeopáticos/definicao.html. Acesso em 30 nov 2016.

ARAÚJO, I. Contabilidade Pública: Teoria e Prática. São Paulo: Saraiva, 2009. 40 p.

BANCO MUNDIAL Informe sobre el desarrollo mundial 2008: agricultura para el desarrollo. Washington, D. C., out. 2008.

BARRERA, A. - Nuevas realidades, nuevos paradigmas: la nueva revolución agrícola in: COMUNIICA, Janeiro Julho 2011, IICA - Instituto Interamericano de Cooperação para a Agricultura

BEUREN, I. M. Como elaborar trabalhos monográficos em contabilidade. $3^{a}$ ed., São Paulo: Editora Atlas S.A., 2008. $195 \mathrm{p}$.

BRASIL. Política Nacional de Agricultura Familiar. Disponível em www.planalto.gov.br/ccivil_03/_ato20042006/2006/lei/111326.htm. Acesso em 01/06/2015.

Lei 4.504/1964. Disponível em: http://www.planalto.gov.br/ccivil_03/leis /L4504.htm. Acesso em 12 ago 2015.

BUAINAIN, A. M. Agricultura Familiar, Agroecologia e Desenvolvimento Sustentável: Questões para Debate. Brasília. IICA: 2006. 136 p.

CAPORAL, F. R. Agroecologia: uma nova ciência para apoiar a transição a agriculturas mais sustentáveis. In. Princípios e Perspectivas da agroecologia. Paraná. Instituto Federal do Paraná. 2011, p.83-119.

CAPORAL, F. R.; COSTABEBER, J. A. 2002. Análise Multidimensional da Sustentabilidade: uma proposta metodológica a partir da agroecologia. Agroecologia e Desenvolvimento Rural Sustentável, Porto Alegre 3, n.13: p. 70-85.

CARMO, M. S. Agroecologia: novos caminhos para a agricultura familiar. Revista Teconologia \& Inovação Agropecuária, p. 28-41, APTA, São Paulo, dezembro de 2008. Disponível em: http://docplayer.com.br/14044710Agroecologia-novos-caminhos-para.html. Acesso em 06 nov 2016.

CERVO, A. L.; BERVIAN, P. A. Metodologia científica. 5.ed. São Paulo: Prentice Hall, 2002. 176 p.

COMISSÃO MUNDIAL SOBRE MEIO AMBIENTE E DESENVOLVIMENTO. Nosso futuro comum. Rio de Janeiro, Ed. Fundação Getúlio Vargas, 1.991.

DEPONTI, C. M. O processo de desenvolvimento rural à luz da perspectiva orientada ao ator: o caso da extensão rural brasileira.2010. Disponível em: https://www.researchgat e.net/publication/238067455_Acesso em: 07 mai 2016.

ELLIS, F.; BIGGS, S. (2001) Evolving Themes in Rural Development 1950s-2000s Development Policy Review 19 (4), 437-448. Blackwell Publishing Ltd. Disponível em: http://www.blackwell-synergy.com/toc/dpr/19/4 Acesso em 05 fev 2016.

FAUTH, E. M. Agricultura familiar: evolução favorável em anos recentes.Ind. Econ. FEE. Porto alegre, v.35 n.4, p.51-60, 2008.

FOOD AND AGRICULTURE ORGANIZATION OF THE UNITED NATIONS (FAO); INSTITUTO NACIONAL DE COLONIZAÇÃO E REFORMA AGRÁRIA (INCRA). Perfil da agricultura familiar no Brasil: dossiê estatístico. Brasília: FAO/INCRA, 1996.

GUILHOTO, J.; J.M. et al. PIB da agricultura familiar: Brasil-Estados. Brasília: Ministério do Desenvolvimento Agrário, 2007.

GONZÁlEZ, S.R, PEREIRA, V.C, SOlGIO, F.K Dal. A perspectiva orientada ao ator em estudos sobre desenvolvimento rural. Perspectivas Rurales. Nueva época, Año 13, N²5, ISSN: 1409-3251

GRISA, C. SCHNEIDER, S. Políticas públicas de desenvolvimento rural no Brasil / Organizadores Catia Grisa [e] Sergio Schneider. - Porto Alegre: Editora da UFRGS, 2015. 624 p.

IBGE,Instituto Brasileiro de Geografia e Estatística. Disponível em: http://www.ibge .gov.br/home/Estatística/populacao/trabalhoerendimento /pnad2013/default.shtm. Acesso em 21 out 2015. 
IBGE CIDADES, 2016. Disponível em: http://cidades.ibge.gov.br/painel

/histórico.php?codmun=410753. Acesso em 10 out 2016.

Censo Agropecuário 2006: agricultura familiar, Brasil, grandes regiões e unidades da federação. Rio de Janeiro, IBGE, 2009.

Síntese de indicadores sociais: uma análise das condições de vida da população brasileira: 2015 / IBGE, Coordenação de População e Indicadores Sociais. - Rio de Janeiro: IBGE, 2015. 137p. - (Estudos e pesquisas. Informação demográfica e socioeconômica, ISSN 15163296; n. 35)

IDESF - Instituto de desenvolvimento social e econômico de fronteiras. Disponível em: http://www.idesf.org.br/ Acesso em 07 de out 2016.

INCRA/FAO. Novo retrato da agricultura familiar: o Brasil redescoberto. Brasília: INCRA/FAO,2000.

KRUEL, A.J. Contribuições da abordagem orientada ao ator às pesquisas em representações sociais: reflexões a partir do estudo dos compromissos dos gestores públicos municipais. XXXIV ENANPAD. Rio de Janeiro. 2010

LONG, N. Development sociology: actor perspectives. London and New York: Routlege, 2001. 293 p.

An Actor-oriented Approach to Development Intervention. In: Rural Life Improvement in Asia: Report of the APO Seminar on Rural Life Improvement for Community Development. 2002.

Sociologia del desarrollo: uma perspectiva centrada en el actor. México: Centro de Investigaciones y Estudios Superiores en Antropología Social: El Colégio de San Luis, 2007.

LONG, N.; PLOEG, J. D. Van Der. Heterogeneidade, ator e estrutura: para a reconstituição do conceito de estrutura. In: Os atores do desenvolvimento rural: perspectivas teóricas e práticas sociais/ organizadores Sergio Schneider e Marcio Gazolla. Porto Alegre: Editora da UFRGS, 2011.

OLIVEIRA, M. M. de. Como fazer pesquisa qualitativa. 2. ed. Rio de Janeiro: Vozes, 2007. 232 p.

PLEIN, C. Desenvolvimento, mercados e agricultura familiar: uma abordagem institucional da pobreza rural. 1. ed. Curitiba: Editora CVR, 2016.

RICHARDSON, Jarry Richardson. Pesquisa social: métodos e técnicas. 3. ed. São Paulo: Atlas, 2009. 424 p.

SARANDON, S. J. Educación y formación en agroecología: una necesidad impostergable para un desarrollo rural sustentable. In: CONGRESSO BRASILEIRO DE AGROECOLOGIA, 2.; CONGRESSO LATINOAMERICANO DE AGROECOLOGIA, Curitiba, 2009. Anais... Curitiba, 2009.

SECCHI, L. Políticas Públicas - Conceitos, esquemas de análise, casos práticos. 1. ed. São Paulo: Cengage Learning, 2011. 188 p.

SCHNEIDER, S.; CAZELLA, A.; MATTEI, L. Histórico, caracterização e dinâmica recente do PronafPrograma Nacional de Fortalecimento da Agricultura Familiar. In: SCHNEIDER, Sergio; SILVA, Marcelo K.; MARQUES, Paulo E.M. (Orgs.) Políticas públicas e participação social no Brasil rural. Porto Alegre (RS): Editora da UFRGS, 2004

SCHNEIDER, S. A pluriatividade e o desenvolvimento rural brasileiro. Cadernos do CEAM, "Agricultura Familiar e Desenvolvimento Territorial - Contribuições ao Debate". Brasilia, ano V, n. 17, p. 23-42, fev. 2005.

SCHNEIDER, S. e GAZOLLA, M. Os atores entram em cena. In: (Orgs.). Os atores do desenvolvimento rural: perspectivas teóricas e práticas sociais. Porto Alegre: Editora da UFRGS, 2011 